\title{
A New Method Using the Circles of Curvature for Solving Equations in $\mathbb{R}^{1}$
}

By

\author{
Bong-kyu ParK* and Sin Hitotumatu**
}

\begin{abstract}
In this paper, we propose a numerical method using the circles of curvature for solving the equations in $R^{1}$, whose order of convergence is cubic. Some numerical examples are given, for which the method works well, while there is shown an example failed by means of the Newton-Raphson's method.
\end{abstract}

\section{$\S 1 . \quad$ New Method for Solving Equations in $\mathbb{R}^{1}$}

Consider the equation

$$
F(x)=0
$$

in $R^{1}$ and let $x_{0}$ be an approximate solution for (1). As have been well known, the circle of curvature at the point $\left(x_{0}, y_{0}\right)=\left(x_{0}, F\left(x_{0}\right)\right)$ on the curve $y=F(x)$ is given by

$$
\left(x-x_{0}+\frac{y_{0}^{\prime}\left(1+y_{0}^{\prime 2}\right)}{y_{0}^{\prime \prime}}\right)^{2}+\left(y-y_{0}-\frac{1+{y_{0}^{\prime 2}}^{2}}{y_{0}^{\prime \prime}}\right)^{2}=\frac{\left(1+y_{0}^{\prime 2}\right)^{3}}{y_{0}^{\prime \prime^{2}}},
$$

provided that $F \in C^{2}$. Therefore, if we define the next approximation $x_{1}$ by the $x$-coordinate of the point at which the circle (2) intersects the $x$-axis, then we obtain the following iterative procedure for solving the equation (1):

$$
\left(x_{n+1}-x_{n}+\frac{y_{n}^{\prime}\left(1+y_{n}^{\prime 2}\right)}{y_{n}^{\prime \prime}}\right)^{2}=\frac{\left(1+y_{n}^{\prime 2}\right)^{3}}{y_{n}^{\prime \prime 2}}-\left(y_{n}+\frac{1+y_{n}^{\prime 2}}{y_{n}^{\prime \prime}}\right)^{2},
$$

i.e.,

$$
\left(x_{n+1}-x_{n}\right)^{2}+2 B_{n}\left(x_{n+1}-x_{n}\right)+C_{n}=0
$$

Communicated by H. Araki, June 24, 1987. Revised November 11, 1987.

* Yuhan Technical College, Seoul, Korea.

** Research Institute for Mathematical Sciences, Kyoto University, Kyoto 606, Japan. 
where $y_{n}=F\left(x_{n}\right), y_{n}^{(i)}=F^{(i)}\left(x_{n}\right), i=1,2$,

and

$$
B_{n}=y_{n}^{\prime}\left(1+y_{n}^{\prime 2}\right) / y_{n}^{\prime \prime}
$$

$$
C_{n}=\left(y_{n}^{2} y_{n}^{\prime \prime}+2 y_{n}\left(1+y_{n}^{\prime 2}\right)\right) / y_{n}^{\prime \prime} .
$$

Substituting $\left(y_{n} / y_{n}^{\prime}\right)^{2}$ for $\left(x_{n+1}-x_{n}\right)^{2}$ in (2), we have

i.e.,

$$
2 B_{n}\left(x_{n+1}-x_{n}\right)=-C_{n}-y_{n}^{2} / y_{n}^{\prime 2},
$$

$$
x_{n+1}=x_{n}-\left(y_{n}^{2} y_{n}^{\prime \prime}+2 y_{n}{y_{n}^{\prime 2}}^{2}\right) /\left(2{y_{n}^{\prime}}^{3}\right) \quad(n \geq 0) .
$$

We shall call the procedure (4) as the first method of the curvature iteration.

On the one hand, if we solve the quadratic equation (3) with respect to $x_{n+1}-x_{n}$, then we have

$$
x_{n+1}-x_{n}=-B_{n}+\operatorname{sign}\left(B_{n}\right)\left(B_{n}^{2}-C_{n}\right)^{1 / 2} .
$$

To avoid the loss of significant digits, we modify (5) as follows;

$$
x_{n+1}=x_{n}-C_{n} /\left(B_{n}+\operatorname{sign}\left(B_{n}\right)\left(B_{n}^{2}-C_{n}\right)^{1 / 2}\right),
$$

which we shall call the second method of the curvature iteration.

\section{§. Order of Convergence}

To examine the order of convergence for (4), let $\alpha$ be a root of (1) and put

$$
\varphi(x)=x-\left(y^{2} y^{\prime \prime}+2 y y^{\prime 2}\right) /\left(2 y^{\prime 3}\right) .
$$

Then, the procedure (4) may be written in the form of $x_{n+1}=\varphi\left(x_{n}\right)$, so that

$$
\begin{aligned}
x_{n+1}-\alpha & =\varphi\left(x_{n}\right)-\varphi(\alpha) \\
& =\varphi^{\prime}(\alpha)\left(x_{n}-\alpha\right)+\frac{1}{2} \varphi^{\prime \prime}(\alpha)\left(x_{n}-\alpha\right)^{2}+\frac{1}{6} \varphi^{\prime \prime \prime}(\alpha)\left(x_{n}-\alpha\right)^{3}+\cdots \\
& =\frac{1}{6} \varphi^{\prime \prime \prime}(\alpha)\left(x_{n}-\alpha\right)^{3}+\cdots,
\end{aligned}
$$

since, as is easily seen, we have

$$
\varphi^{\prime}(\alpha)=\varphi^{\prime \prime}(\alpha)=0,
$$

and

$$
\varphi^{\prime \prime \prime}(\alpha)=\left(2 y^{\prime}(\alpha) y^{\prime \prime}(\alpha)+3 y^{\prime \prime}(\alpha)^{2}\right) /\left(2 y^{\prime}(\alpha)^{2}\right),
$$

provided that $F \in C^{5}$. This implies that the order of convergence for (4) is 
cubic, if $F \in C^{5}$.

\section{§3. Numerical Examples}

Example 1. Table 3-1 shows the results of computation for both the Newton-Raphson method and the second method applied to the equation $\sin (2.1 x-0.6)=0$ with the approximation, $x_{0}=1$. As we have observed, the second method converges, but the Newton-Raphson's method fails. The same situation occurs for the value $x_{0}$ in the interval $[1,2]$.

(Table 3-1)

\begin{tabular}{|c|c|c|}
\hline Times of iteration & Newton Raphson & Curvature Iteration \\
\hline 1 & -5.7149519920349 & 1.69681475779063 \\
2 & -5.6982652358711 & 1.78123734436566 \\
3 & -5.6982718813119 & 1.78171084762747 \\
4 & -5.6982721689230 & \\
& $\ldots \ldots \ldots \ldots \ldots \ldots \ldots \ldots$ & (second formula) \\
$y$ & failure & $-8.7422783679 D-08$ \\
\hline
\end{tabular}

* Here " $1 "$ is given as an initial approximation.

Example 2. In Table 3-2, we compare the methods (4) and (5) with the Newton-Raphson's method for the following equations.

1. $F(X)=X^{3}-X^{2}-1=0$

2. $F(X)=X^{4}-3 X^{3}-X^{2}+2 X+3=0$

3. $F(X)=X^{5}-2 X^{4}-4 X^{3}+X^{2}+5 X+3=0$

4. $F(X)=X^{6}-8 X^{4}-4 X^{3}+7 X^{2}+13 X+6=0$

5. $F(X)=X^{7}+X^{6}-8 X^{5}-12 X^{4}+3 X^{3}+20 X^{2}+19 X+6=0$

(Table 3-2)

\begin{tabular}{|c|c|c|c|c|c|c|c|}
\hline \multicolumn{2}{|c|}{$\begin{array}{l}\text { Degree of } \\
\text { Equation }\end{array}$} & \multicolumn{3}{|c|}{$\begin{array}{l}\text { Accuracy of the Last } \\
\text { Root to Be Found }\end{array}$} & \multicolumn{3}{|c|}{ Times of Iteration } \\
\hline & & Newton & $\begin{array}{c}\text { First } \\
\text { Formula }\end{array}$ & $\begin{array}{l}\text { Second } \\
\text { Formula }\end{array}$ & Newton & $\begin{array}{c}\text { First } \\
\text { Formula }\end{array}$ & $\begin{array}{l}\text { Second } \\
\text { Formula }\end{array}$ \\
\hline$(* 1)$ & 3 & E-016 & E-016 & E-016 & 5 & 4 & 4 \\
\hline$(* 1)$ & 4 & E-016 & E-016 & E-016 & 5 & 3 & 3 \\
\hline$(* 1)$ & 5 & E-014 & E-015 & E-015 & 4 & 4 & 4 \\
\hline$(* 1.5)$ & 6 & E-015 & E-015 & E-015 & 3 & 2 & 2 \\
\hline$(* 1.5)$ & 7 & E-015 & E-014 & E-015 & 3 & 2 & 2 \\
\hline
\end{tabular}

(* Initial approximation) 
As confirmed in Table 3-2, the number of iterations with which our method converges is fewer than the Newton-Raphson's method. 